\title{
$X$-ray imaging of horizontal jets in gas fluidised bed nozzles
}

\author{
Luca Panariello ${ }^{a, b}$, Massimiliano Materazzi ${ }^{b,}{ }^{,}$, Roberto Solimene ${ }^{a}$, Piero Salatino ${ }^{a}$, Paola \\ Lettieri $^{\mathrm{b}}$ \\ a Dipartimento di Ingegneria Chimica, dei Materiali e della Produzione Industriale, Universita' degli Studi di \\ Napoli Federico II, P.le Tecchio, 80-80125 Napoli, Italy \\ ${ }^{\mathrm{b}}$ Department of Chemical Engineering, University College London, Torrington Place, London WC1E TJE, UK
}

\begin{abstract}
A study on the hydrodynamics in gas-solid fluidized beds where the primary gas injection is achieved through a nozzle-type gas distributor has been carried out, using an innovative X-ray imaging technique. Qualitative and quantitative results are reported, with particular regards to the jet penetration length. Results show that the lighter and the finer are the particles, the larger is the jet penetration. A new non-dimensional correlation is proposed, since the experimental data do not match predictions available in literature, based on hydrodynamic scaling and Froude number. The new correlation takes into account the effects of jet velocity, particle density and particle size. A tentative mechanistic explanation for the departure from purely hydrodynamic scaling is offered.
\end{abstract}

\section{Introduction}

Gas distribution in fluidised beds may be accomplished with a variety of devices whose design, operational criteria and performance are widely addressed in the general fluidisation literature $[1,2]$.

The nozzle type of distributor has been found to be very effective for high temperature fluidised bed reactors and is the recommended type for most applications at industrial scale. Nozzles are usually screwed or welded to a flat horizontal plate which forms the roof of an air supply plenum chamber. If the nozzles are correctly spaced and the holes properly sized, this type of distributor gives excellent fluidisation and trouble-free operation for extended periods of service [1]. Due to the great impact jets have on the hydrodynamics and gas transfer within the bed, it is highly important to establish the correct jet penetration for the design and operation of nozzles in fluidized bed reactors. Improper nozzle spacing and density in the design phase may result in poor gas distribution and incorrect 
penetration lengths and negatively impact vessel/reactor sizing, blower sizing, particle attrition, performance and durability of refractory lining, hence product yield and reactor lifetime.

Despite extensive literature on the subject, the information on jets in fluidized beds available in the literature is still lacking and/or limited to specific case studies. Most studies address gas and solids flow properties of fluidised beds in small- or medium-scale transparent vessels operated at ambient conditions, some in 2-D configuration, with measurements made through viewing screens or with the aid of sensors located in the bed [3-9]. Observations are not only restricted but often distorted by the presence of walls and internal surfaces or from effects of downscaling. Consequently, most of the studies on jet measured by such techniques fail to detect interactions between adjacent nozzles or pipes because of the stabilising effects of the walls $[10,11]$. Furthermore, most studies reported observations of jet penetrations from single isolated orifices employing a background flow of gas through a porous plate in an attempt to simulate the effects of multiple nozzles or orifices [6]. These conditions are far from being representative of those encountered in commercial fluidised beds, where jets have to penetrate through a stagnant bed of particles laying at the bottom of the reactor.

Non-invasive experimental techniques are invaluable for providing a detailed insight into jet penetration and general hydrodynamic patterns of fluidised beds at larger scale [12]. One such technique involves the use of X-rays to observe and quantify gas and solid flow patterns. In fact X-ray imaging overcome all the limitations mentioned above and provide information that cannot be obtained by other techniques. Since its embryonic applications, this technique has gained time- and space resolution and has been empowered to the point of providing an invaluable aid for improved design of internal structures such as gas distributors and heat transfer surfaces in industrial units [13].

This study addresses X-ray imaging of the jetting region of a gas fluidized bed, with the aim of estimating jet penetration for different materials at simulated but realistic conditions and in reactor configurations which are representative of full scale industrial operation. The experimental data obtained in this study are matched against prediction of available correlations, and a new empirical correlation for horizontal jet penetration is proposed.

\section{Materials and methods}

\subsection{Reactor and Nozzle}

The experimental apparatus consists of a fluidization column equipped with a single nozzle acting as gas distributor. The column consists of a $150 \mathrm{~mm}$ ID Perspex tube closed at the bottom by means of a plate through which a pipe threaded at the exit is fitted for the 
connection to the nozzle. The nozzle-connected pipe, with a $12 \mathrm{~mm}$ internal diameter, is located along the axis of the vessel.

Air is injected in the tube using an industrial scale nozzle located at its the centre. The nozzle has been realized in Acrylonitrile-Butadiene-Styrene with a 3D printer, and is characterized by an orifice diameter $d_{o}=4.1 \mathrm{~mm}$ (Figure 1). Two different orifice configurations have been tested in order to analyse the influence of the number of jets: a single orifice nozzle and a double orifice nozzle, with the two orifices forming an angle of $180^{\circ}$. The nozzle was located at the centre of the fluidization column, at a distance from the bottom of the column of $25 \mathrm{~cm}$.

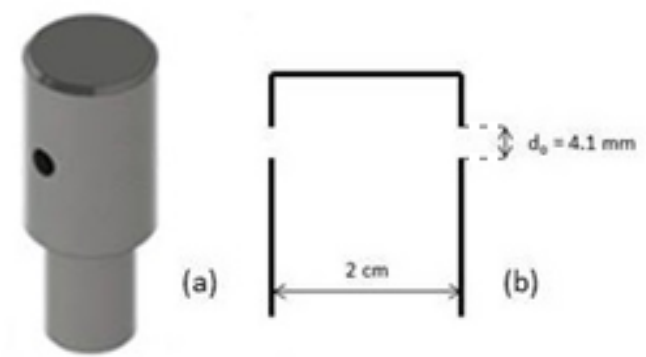

Figure 1 - (a) Nozzle design (double orifice configuration), (b) Nozzle section

The fluidizing gas is technical air metered to the vessel through a pressure regulator and a flowmeter.

\subsection{Materials}

Three different bed materials (Table 1) have been used in the tests, characterized by different median particle size, particle densities and incipient fluidization velocity $u_{m f}$, computed according to Wen and $\mathrm{Yu}$ [14]. All the materials belong to the Group B of the Geldart classification of powders [15]. 
Table 1: Material Properties

\begin{tabular}{|c|c|c|c|c|c|c|c|c|}
\hline & $\begin{array}{l}\text { Material } \\
\text { Name }\end{array}$ & $\boldsymbol{\rho}_{\boldsymbol{p}}\left[\mathrm{kg} / \mathrm{m}^{3}\right]$ & $\begin{array}{l}d_{10} \\
{[\mu \mathrm{m}]}\end{array}$ & $\begin{array}{l}d_{50} \\
{[\mu \mathrm{m}]}\end{array}$ & $\begin{array}{l}d_{90} \\
{[\mu \mathrm{m}]}\end{array}$ & $\begin{array}{l}\text { Sauter mean } \\
\text { diameter }[\mu \mathrm{m}]\end{array}$ & $\boldsymbol{u}_{\boldsymbol{m} f}[\mathrm{~cm} / \mathrm{s}]$ & $\begin{array}{l}\text { Geldart } \\
\text { Group }\end{array}$ \\
\hline Material A & Sand & 2500 & $\begin{array}{l}118 \\
182 \\
263\end{array}$ & $\begin{array}{l}176 \\
250 \\
365\end{array}$ & $\begin{array}{l}263 \\
344 \\
511\end{array}$ & $\begin{array}{l}185 \\
258 \\
380\end{array}$ & $\begin{array}{l}3.9 \\
7.6 \\
16.6\end{array}$ & B \\
\hline Material B & Natural rutile & 4200 & $\begin{array}{l}89 \\
193\end{array}$ & $\begin{array}{l}150 \\
268\end{array}$ & $\begin{array}{l}252 \\
369\end{array}$ & $\begin{array}{l}162 \\
276\end{array}$ & $\begin{array}{l}5 \\
14.7\end{array}$ & B \\
\hline Material C & $\begin{array}{l}\text { Synthetic } \\
\text { rutile }\end{array}$ & 3200 & $\begin{array}{l}107 \\
154 \\
209\end{array}$ & $\begin{array}{l}155 \\
215 \\
307\end{array}$ & $\begin{array}{l}227 \\
300 \\
454\end{array}$ & $\begin{array}{l}163 \\
222 \\
320\end{array}$ & $\begin{array}{l}3.9 \\
7.2 \\
15\end{array}$ & B \\
\hline
\end{tabular}



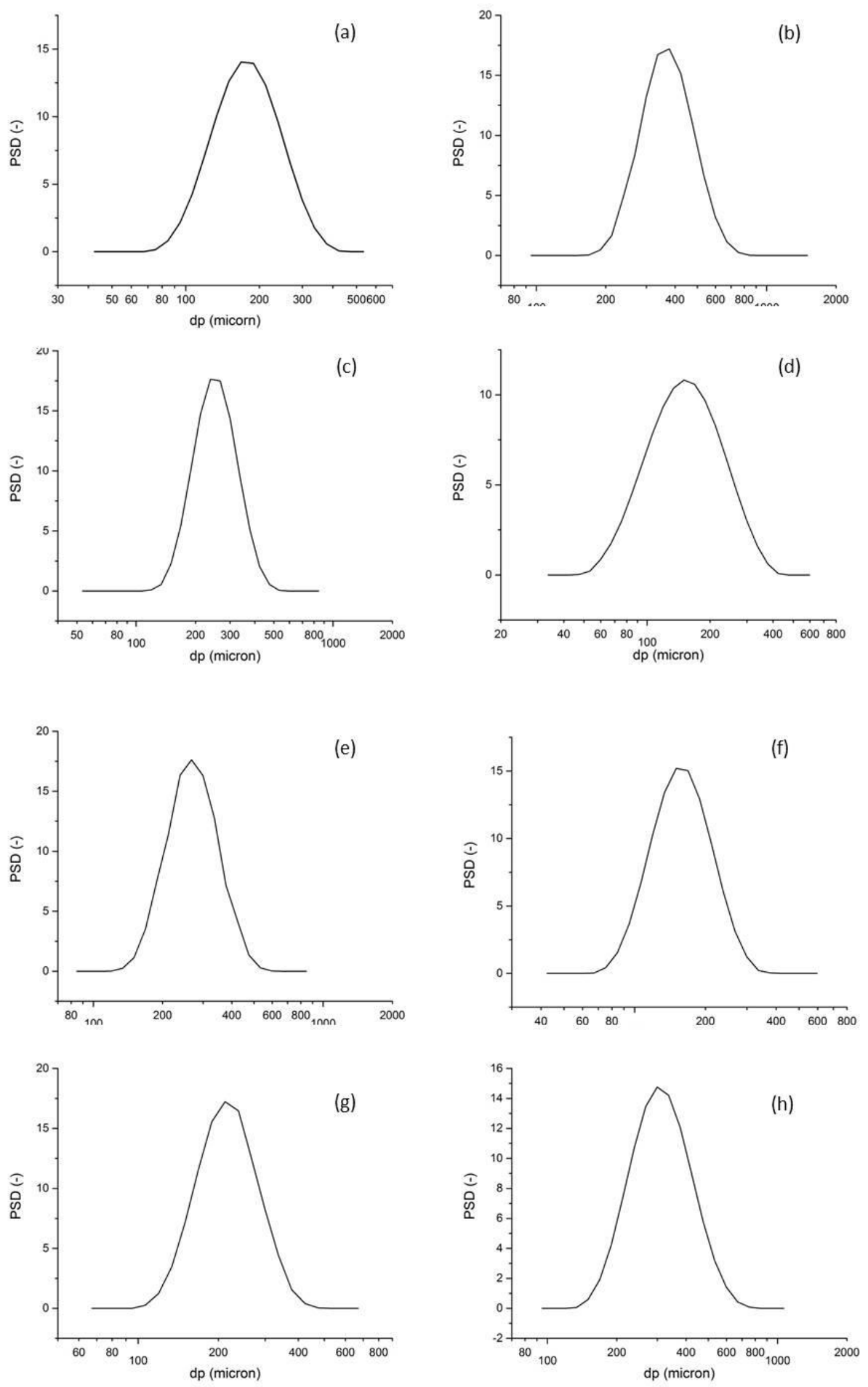

Figure 2 - Particle size distributions of the materials tested: (a) Material A $d_{p}=175 \mu \mathrm{m}$, (b) Material A $d_{p}=$ $250 \mu \mathrm{m}$, (c) Material A $d_{p}=365 \mu \mathrm{m}$, (d) Material B $d_{p}=150 \mu \mathrm{m}$, (e) Material B $d_{p}=268 \mu \mathrm{m}$, (f) Material $\mathrm{C} d_{p}=155 \mu \mathrm{m}$, (g) Material C $d_{p}=215 \mu \mathrm{m}$, (h) Material C $d_{p}=307 \mu \mathrm{m}$

In order to investigate the effects of different particle sizes, the three materials have been sieved, each class characterized by a narrower particle size distribution (Figure 2 and Table 2 ), so that for each class the particle size has been considered equal to its median diameter. 
Three size classes were obtained for material A $\left(d_{p}=175 \mu \mathrm{m}, d_{p}=250 \mu \mathrm{m}\right.$ and $d_{p}=$ $365 \mu \mathrm{m})$, two for material $\mathrm{B}\left(d_{p}=150 \mu \mathrm{m}\right.$ and $\left.d_{p}=268 \mu \mathrm{m}\right)$ and three for material $\mathrm{C}$ $\left(d_{p}=155 \mu \mathrm{m}, d_{p}=215 \mu \mathrm{m}\right.$ and $\left.d_{p}=307 \mu \mathrm{m}\right)$.

Table 2: Model parameters

\begin{tabular}{c|c|c|c}
\hline & $\boldsymbol{d}_{\boldsymbol{p}}[\boldsymbol{\mu m}]$ & $\boldsymbol{\alpha}$ & $\boldsymbol{\beta}$ \\
\hline \multirow{3}{*}{ Material A } & 175 & 1.79 & 0.43 \\
& 250 & 1.71 & 0.43 \\
& 365 & 1.29 & 0.44 \\
\hline \multirow{2}{*}{ Material B } & 150 & 1.32 & 0.44 \\
& 268 & 1.23 & 0.46 \\
\hline \multirow{3}{*}{ Material C } & 155 & 1.66 & 0.42 \\
& 215 & 1.51 & 0.44 \\
\hline
\end{tabular}

\subsection{Experimental procedure, X-ray imaging and post-processing}

For every experiment, the reactor was filled with the solid particles up to a height of $65 \mathrm{~cm}$, equivalent to $40 \mathrm{~cm}$ above the nozzle level. The flow rate was set to the maximum value tested, and then decreased down to the minimum value tested. At every flow rate, images were recorded using the X-ray system. Every flow rate corresponds to a different jet velocity $v_{j}=\frac{Q}{\pi d_{o}^{2} / 4 n}$, where $Q$ is the flow rate, $d_{o}$ is the orifice diameter and $n$ is the number of orifices. Then the images were post-processed, and from the corrected images voidage distribution and jet penetration were measured.

The new high power pulsed X-ray generation system (Lettieri \& Yates 2013) has been employed to record the images in the jetting area. The system is able to provide X-ray pulses down to $200 \mu$ s with an intensity of up to $450 \mathrm{~mA}$ at a voltage variable from $50 \mathrm{kV}$ to $150 \mathrm{kV}$. Two focal spots may be selected $(0.6 \mathrm{~mm}$ and $1.2 \mathrm{~mm})$, and the target can be rotated at either $50 / 60 \mathrm{~Hz}$ or $180 \mathrm{~Hz}$, depending on the power required. X-rays are detected on a 30 $\mathrm{cm}$ industrial X-ray Image Intensifier, optically coupled to a $1024 \times 1024$ pixel high speed digital CCD camera. The camera is triggered by the control software, which in turn is triggered by the $X$-ray generator at frame rates from 24 to 72 Frames per second. The configuration of the X-ray system and the rig used in this study are sketched in Figure 3. Different $X$-ray settings were adopted for each material in order to record images at the best quality possible. The images were then processed in Matlab to improve their quality by subtracting a reference image of the static bed and correcting the pincushion effect, as shown in Figure 4. 


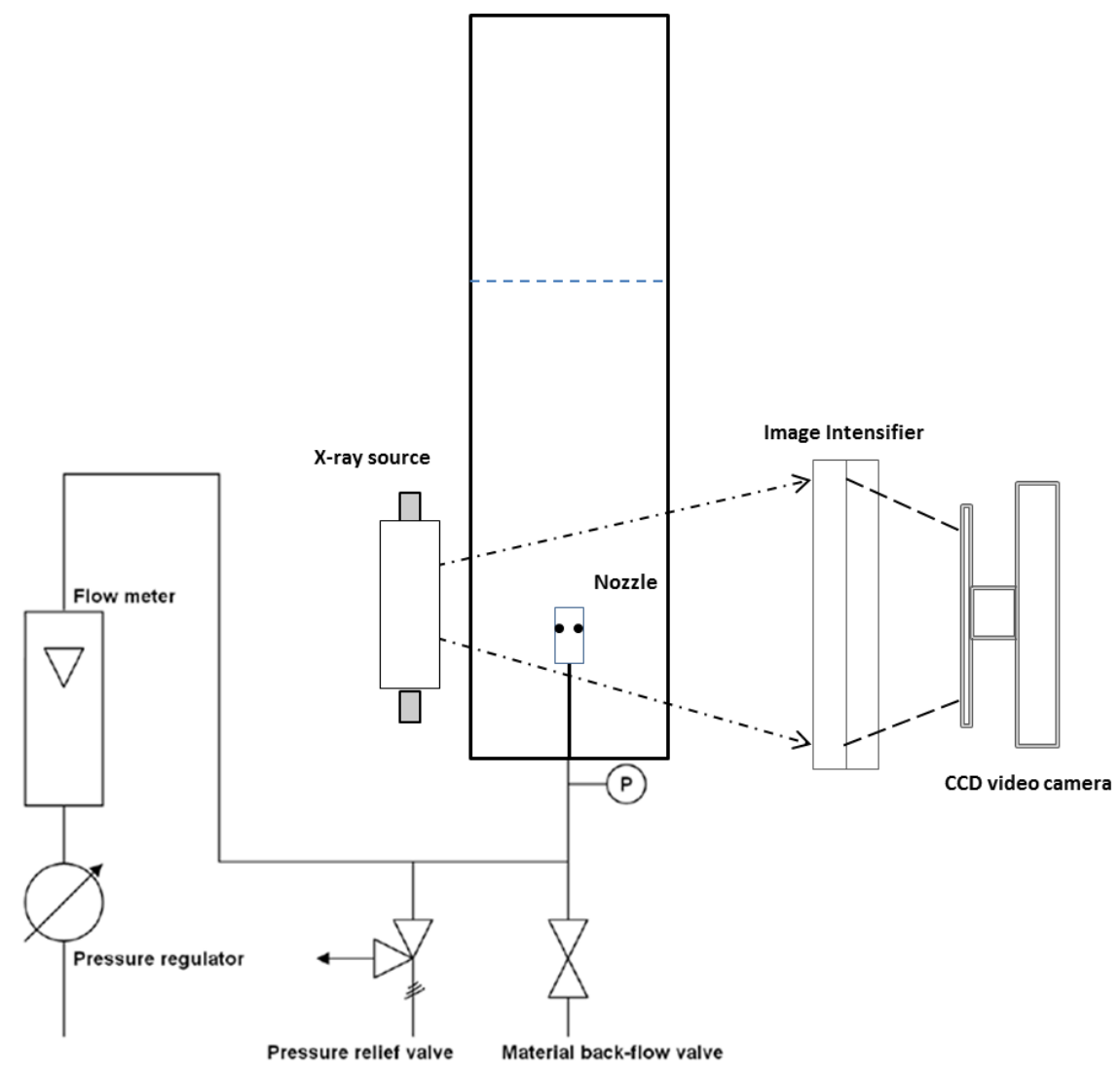

Figure 3 - Rig schematic and X-ray configuration

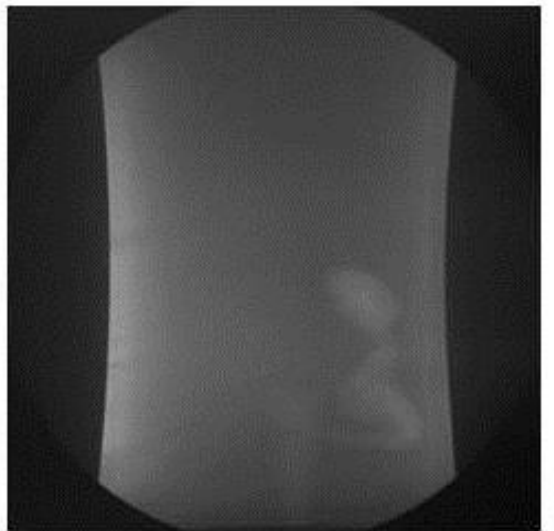

(a)

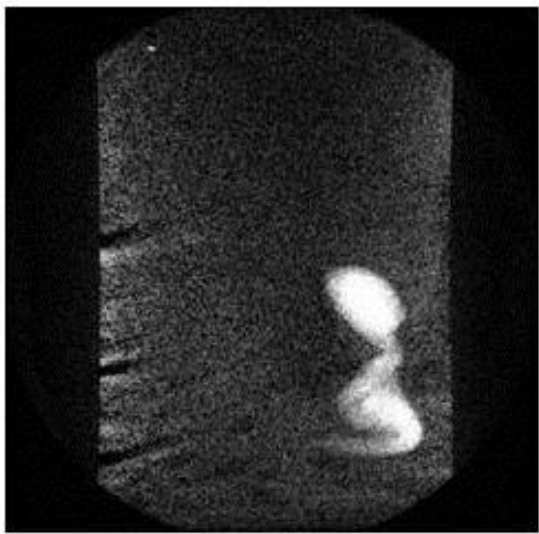

(b)

Figure 4-(a) A raw image of a jet from a nozzle and (b) the same image after post processing

From the images recorded it was possible to measure the voidage distribution in the jetting area, by using the Lambert-Beer equation [16].

$$
I=I_{0} \exp \left(-\mu_{m} \rho_{b} l\right)
$$

Where $I$ is the transmitted intensity, $I_{0}$ the incident intensity, $\mu_{m}$ the attenuation coefficient of the material, $\rho_{b}$ the bulk density of the material and $l$ the optical path. The voidage has 
been measured by applying equation (1) to 720 images (corresponding to approximately 10 seconds recording) and then converted into a single image, representative of the timeaveraged voidage distribution. By applying equation (1) to the images, the voidage values obtained are not representative of the punctual values, but consist in averaged values along chords corresponding the depth of the bed. However, these maps allow a significant qualitative analysis of the hydrodynamic structures in the jetting region, which results clearly identifiable in this way.

Furthermore, the good resolution of the images obtained with the X-ray system allowed visualising and measuring the horizontal jet penetration $L_{j}$ (Figure 5). Measurements were taken at different flow rates, with different materials and different particle sizes in order to investigate the effect of these parameters on $L_{j}$.
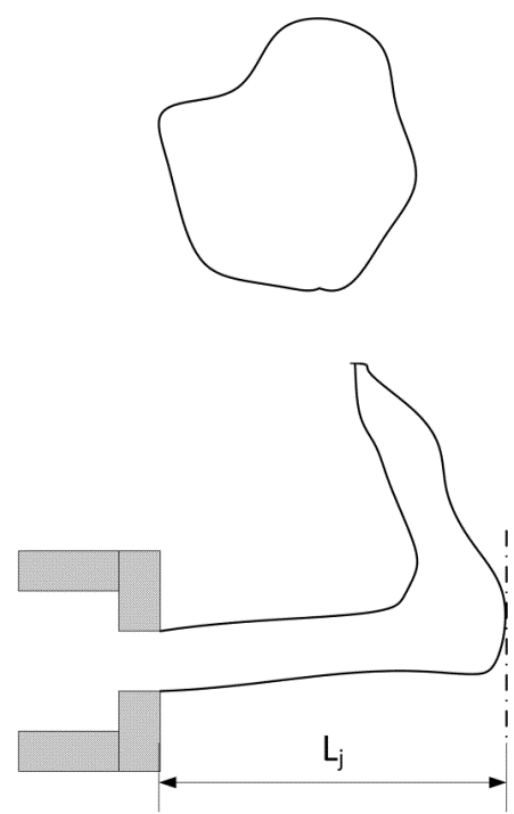

Figure 5 - Jet penetration sketch

\section{Results and discussion}

The images recorded enabled a preliminary qualitative characterization of the hydrodynamics associated to the gas distribution area. Their digital post-processing was directed to obtain quantitative information on jet penetration length.

\subsection{Single orifice configuration}

The single orifice configuration has been tested covering a range of different flow rates from below to above the incipient fluidization velocity $u_{m f}$. The materials tested belong to Group B of Geldart classification of powders [15], so $u_{m f} \approx u_{m b}$, where $u_{m b}$ is the minimum 
bubbling velocity. Hence, the presence of bubbles indicates a condition of local fluidization in the bed.
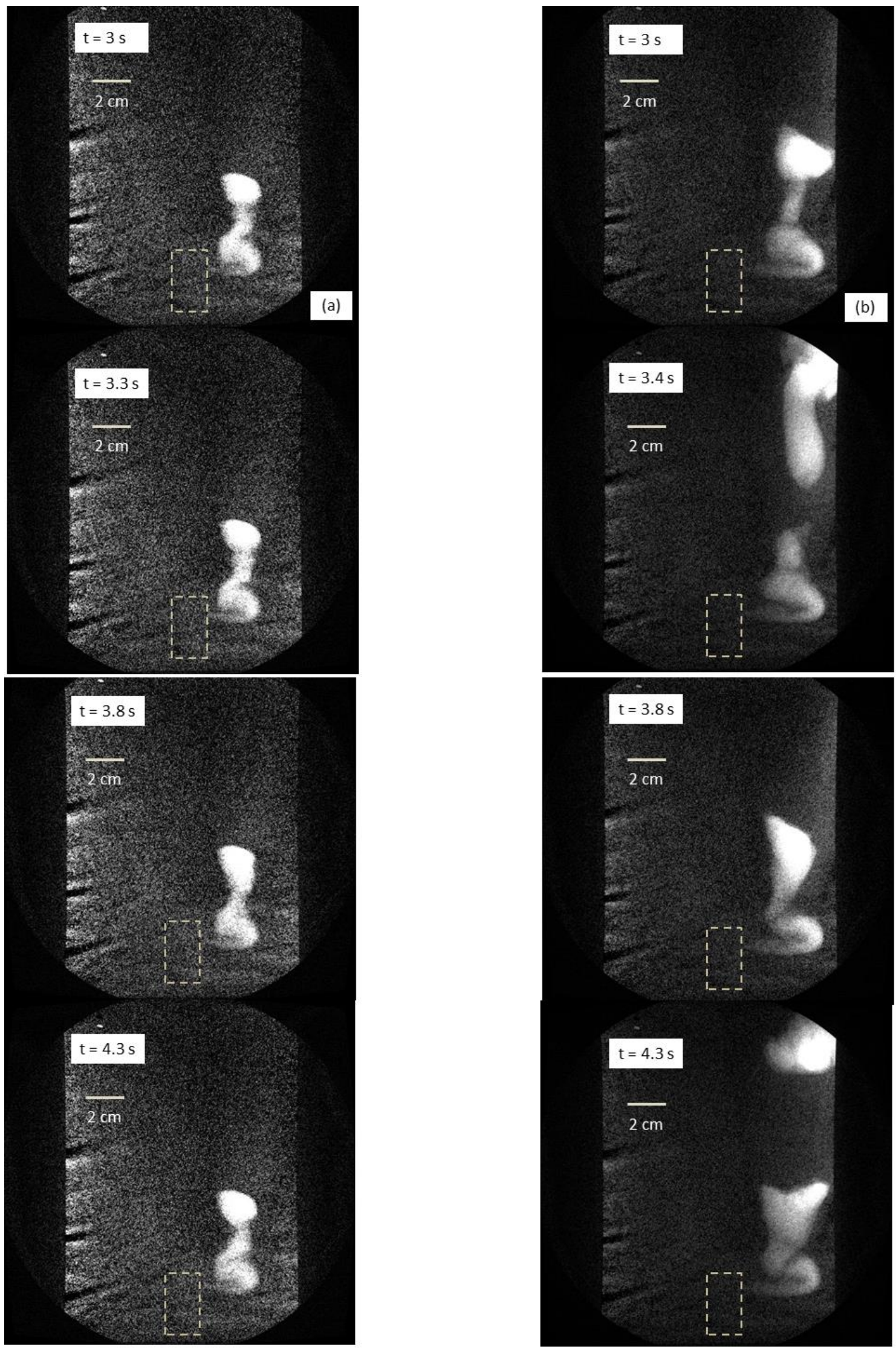
Figure 6 - Jet evolution within 1.3 seconds. Single orifice nozzle, Material A, (a) jet velocity of $39 \mathrm{~m} / \mathrm{s}$ (flow rate of $30 \mathrm{~L} / \mathrm{min}$ ), (b) jet velocity of $57 \mathrm{~m} / \mathrm{s}$ (flow rate of $45 \mathrm{~L} / \mathrm{min}$ ). Dotted line indicates the position of the nozzle (2 cm diameter)

Figure 6 shows the evolution of a single jet at two different flowrates. Figure 6 (a) refers to a condition where no bubbles are observed: here the jet appears with a peculiar meandering S-shaped path. A stable void appears on top of the plume of the jet, which is absorbed in the emulsion phase. On the other hand, in Figure 6 (b) bubbles can be seen detaching from the plume of the jet and rising along the fluidized bed. However, even in this case the jet appears with the same particular S-shape.

Wall effects on the S-shape of the jet can be confidently ruled out, since further tests performed with larger vessels did not show any dependence with the column diameter.

Bubbles appear at flow rates below that of minimum fluidization referred to the whole bed cross section in both single and double orifice nozzle configuration. This suggests an uneven distribution of the gas through the cross section of the bed.

As regards the jet penetration, Figure 7 shows its increasing trend with the increase of the jet velocity.

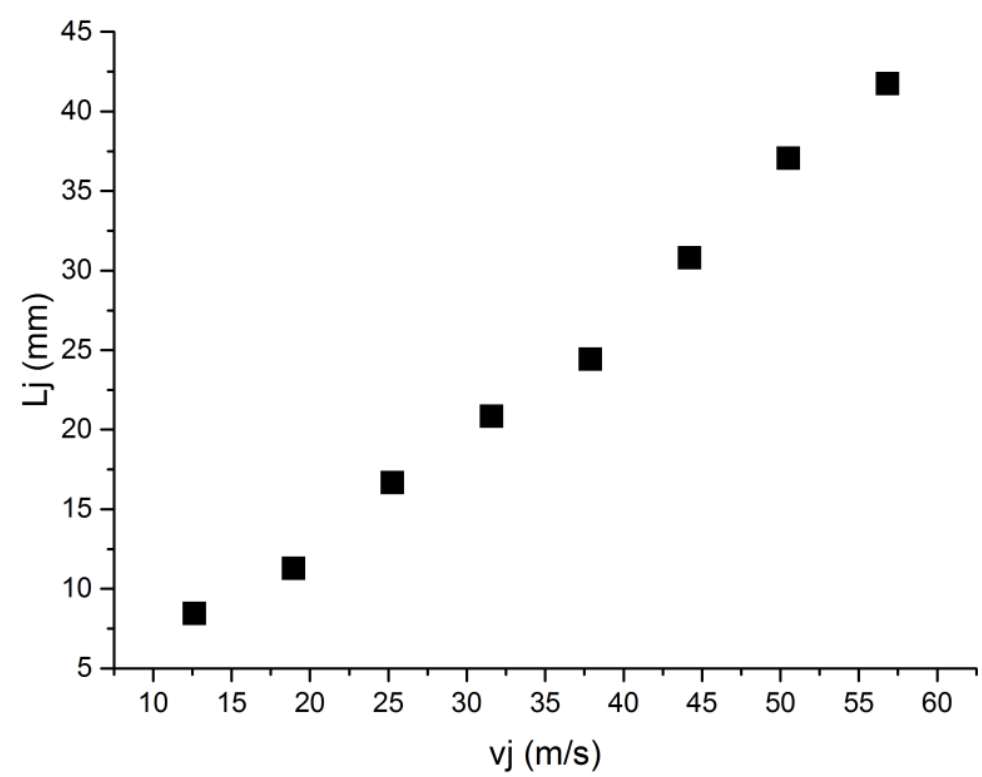

Figure 7 - Jet penetration at different jet velocities for the single orifice configuration (Material A)

\subsection{Double orifice configuration}


The same investigation has been performed with the double orifice configuration. Here the evolution of the hydrodynamics when increasing the flow rate appears more complex, as shown in Figure 8 to 10. In all cases the two jets tend to interact with each other: at low flow rates (Figure 8) no fluidization occurs, and the jets arch to coalesce with each other to form a 'horseshoe' structure, also called gas bridge $[17,18]$. This type of jet coalescence usually occurs at low nozzle flowrates, short separation distances of two orifices, or when gas is discharged from vertical nozzles. At lower flowrates, a spherical cap, high voidage region forms in the interaction zone of the two jets. Gas is believed to circulate in this region.

When increasing the flow rate (Figures 9,10 ) the gas bridge structure breaks down to give rise to two distinct fluidizing jets. The jets still interact with each other by conveying to the centre of the reactor, forming a triangular structure above which bubbles break off [1]. Above the jets a smooth bubbling is observed across the bed [1,7,19-21].
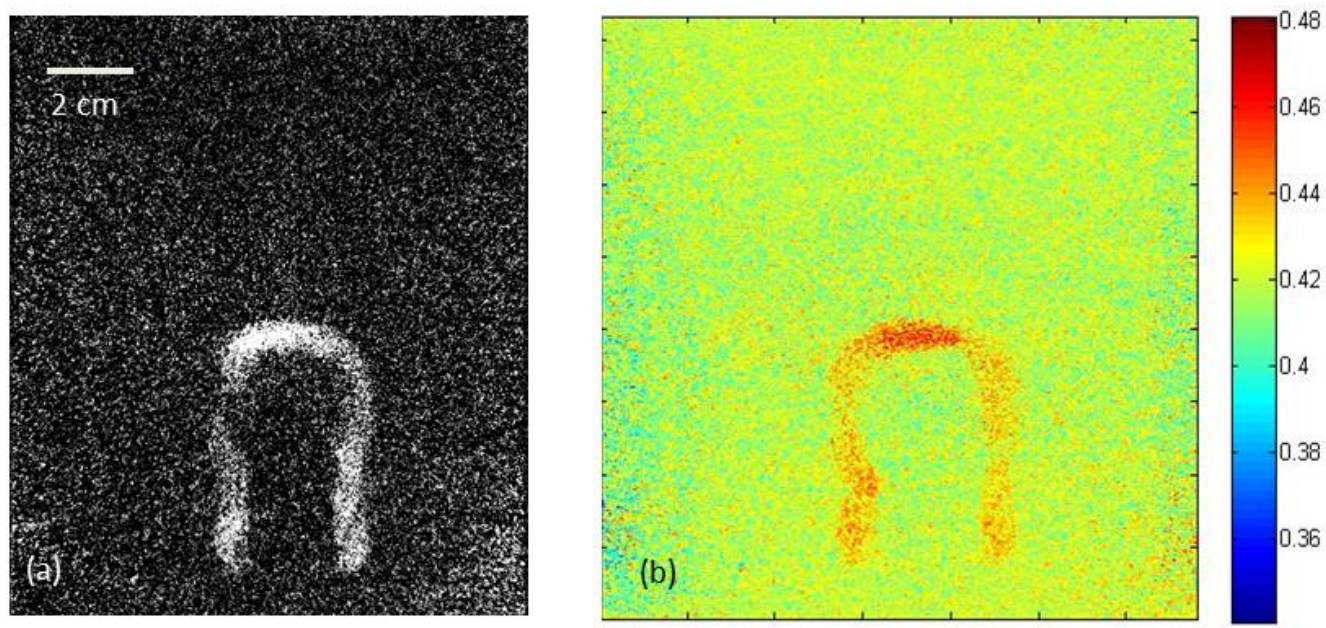

Figure 8 - Double orifice, flow rate of 20 Litre/min, Material A: (a) X-ray image, (b) voidage distribution
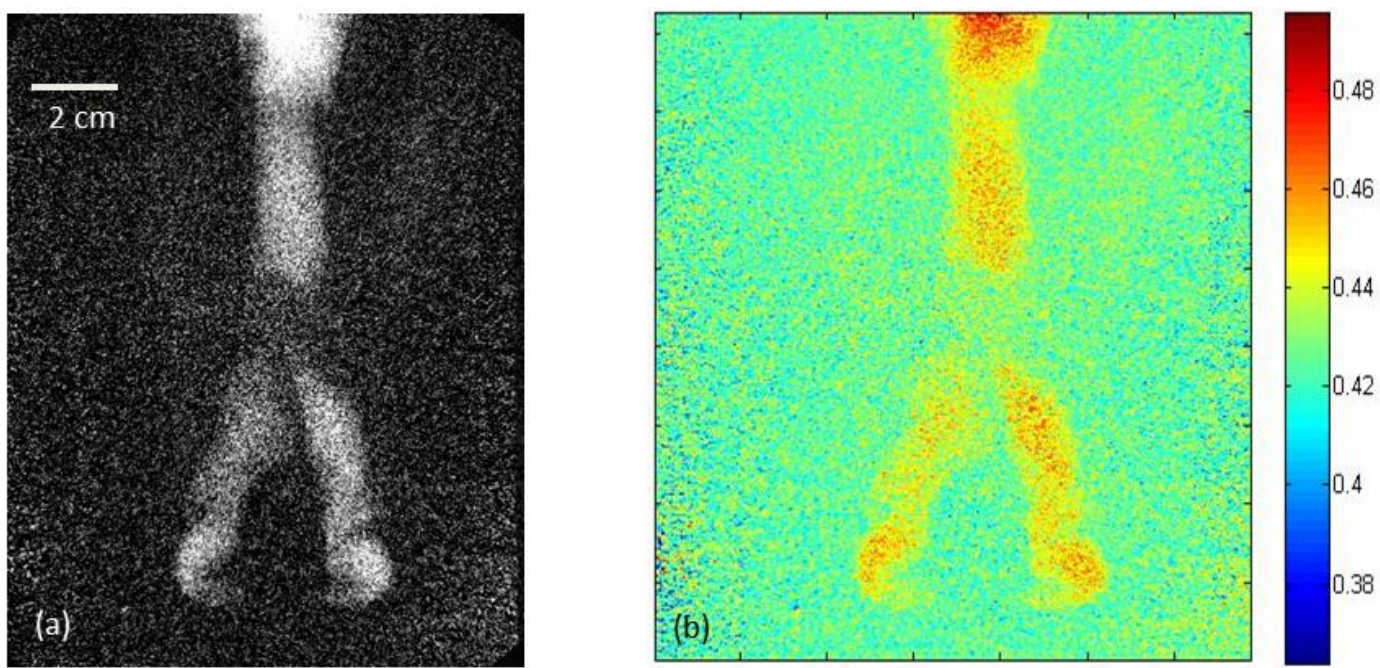
Figure 9 - Double orifice, flow rate of 35 Litre/min, Material A: (a) X-ray image, (b) voidage distribution
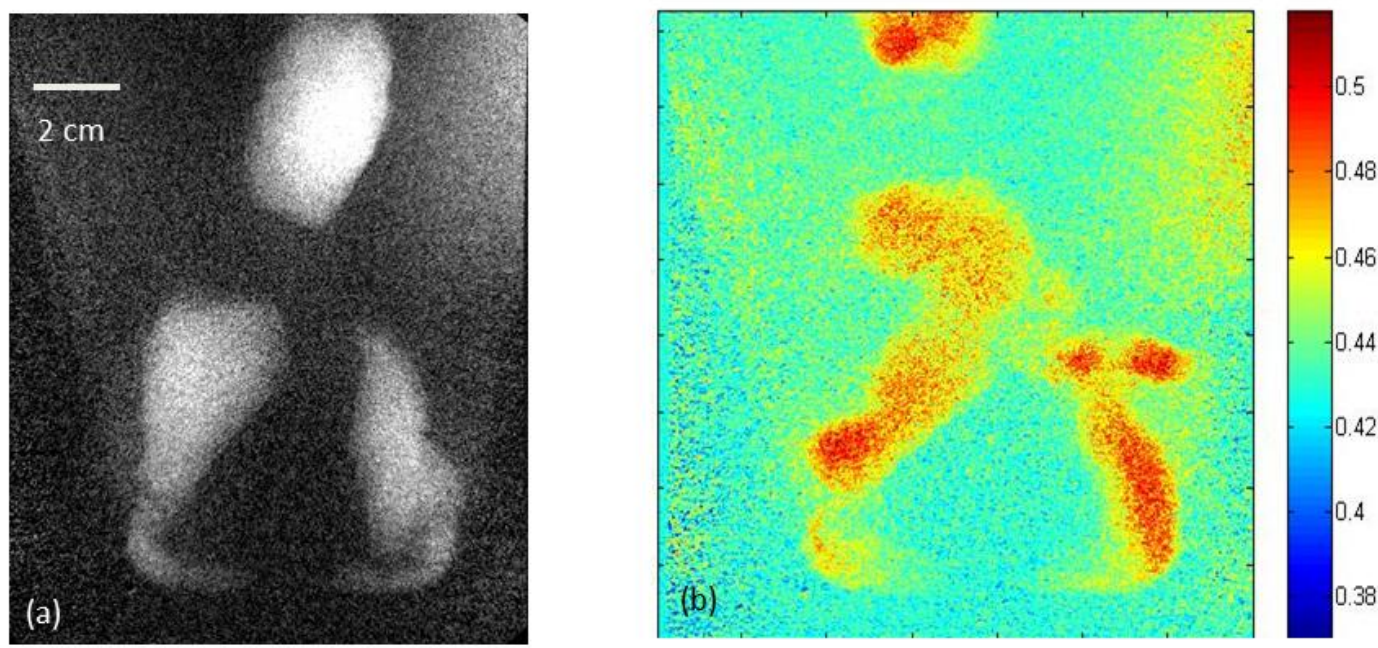

Figure 10 - Double orifice, flow rate of 60 Litre/min, Material A: (a) X-ray image, (b) voidage distribution

This behaviour seems to be in line with the experiments of Liseth $[22,23]$, who showed that when horizontal buoyant jets are discharged simultaneously from a diffuser, the plumes tend to bend backward because of pressure interaction. The plumes eventually merge at a certain height above the diffuser, which is found to increase with holes spacing and jet Froude number.

As for the single jet configuration, an increasing trend in the jet penetration is observed when increasing the two jets velocity (Figure 12).

\subsection{Comparison between single and double orifice configurations}

A first comparison between the two orifice configurations is possible by qualitatively analysing the voidage distributions at a given flow rate. Avoiding stagnant region is one of the most challenging aspect when using this type of gas distributor [1]: gas results to be more equally distributed using the double orifice configuration, with less stagnant regions when compared with the single orifice configuration (Figure 11), so the increased number of orifices warrants better gas distribution in the jetting area. 


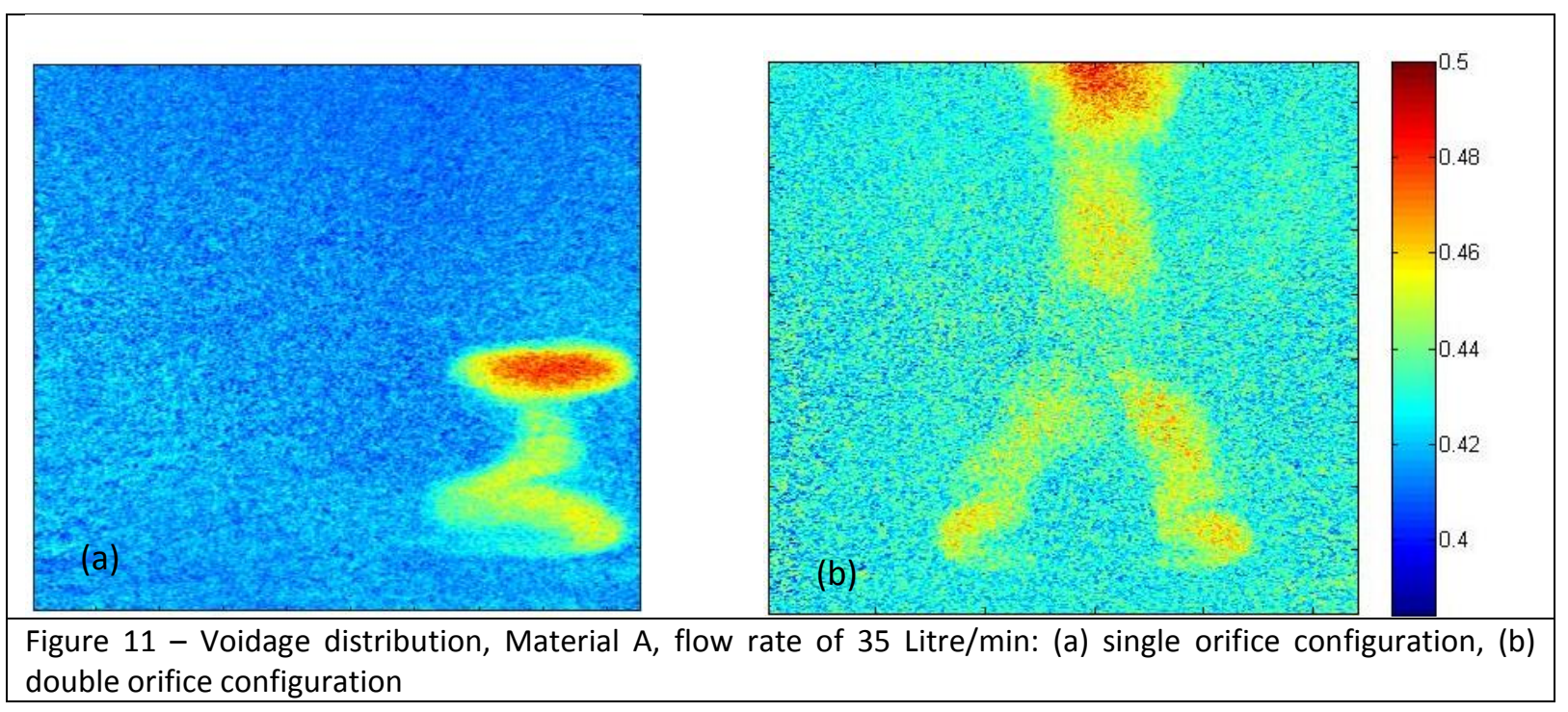

In Figure 12 single and double orifice configurations are compared in terms of jet penetration. It appears that the jet penetration is not significantly affected by the orifice configuration adopted. The standard deviation at low jet velocities (up to $20 \mathrm{~m} / \mathrm{s}$ ) is in the order of the $10 \%$ of the mean value, while dropping significantly at higher jet velocities, in the order of the $2 \%$ of the mean value. This is due to the much higher definition of the images at higher flow rates, where the hydrodynamic structures are much clearly identifiable.

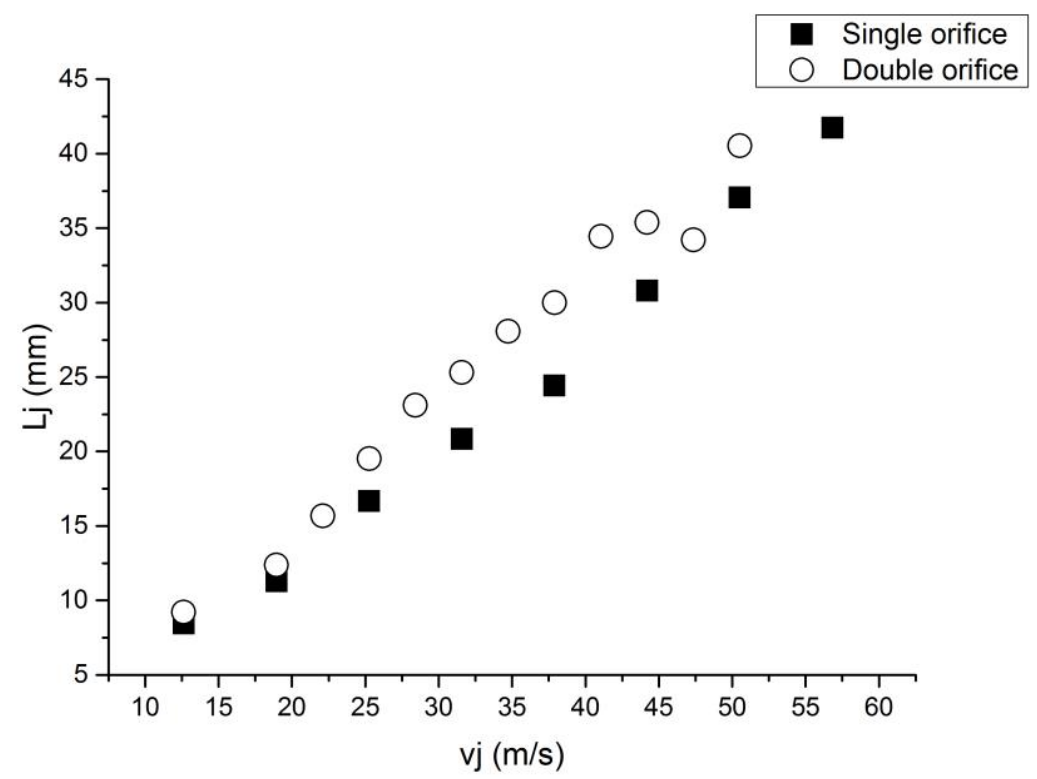

Figure 12 - Jet penetration for single and double orifice configuration at different jet velocities (Material A)

\subsection{Jet penetration correlation}


According to the approach proposed by Yang [24], the relationship between the gas momentum at the orifice and gravity forces acting on the jet can be written as a function of the Froude number, from which the penetration length can be obtained:

$$
\frac{L_{j}}{d_{o}}=\alpha F r^{\beta}
$$

where $\mathrm{Fr}$ is the two phase Froude number $\mathrm{Fr}=\frac{\rho_{o}}{\rho_{p}-\rho_{o}} \frac{v_{j}^{2}}{g d_{o}}, \rho_{o}$ is the fluid density, $\rho_{p}$ is the particle density, $v_{j}$ is the jet velocity, $d_{o}$ is the orifice diameter and $g$ is the gravitational acceleration. The Froude number integrates the effects of particle size, jet diameter and jet gas velocity, and represents the ratio of the inertial force of gas at the nozzle and the gravity force on particles. In literature many correlations are available based on the same basic concept $[3,7-9,11,19,25-27]$ : however the discrepancy between the prediction from different correlations sometimes can be more than an order of magnitude [28-31].

Briens et al. [3] showed that the correlation developed by Benjelloun [26] matches their experimental data more closely. In this section the experimental data obtained for material A are compared with the predictions based on the Benjelloun correlation (Figure 13). The plot indicates that the correlation overestimates the jet penetration observed in the experiments. This result has been proven by Yates $[11,19]$ and Newton $[10]$ to be imputable to the invasive measuring technique based on the use of 2D reactors: here the walls exert a stabilizing effect on the jet, causing an increase in the penetration. Therefore correlation developed in 2D reactors are not accurate to predict the jet penetration in 3D reactors and, generally, in industrial cases [12,32]. The data gathered have then been compared with Yates correlation for the jet penetration prediction [11]. These predicted values match more closely the experimental one. This is an expected result, since the same technology (X-ray imaging) has been used by Yates to develop his correlation. The discrepancy between the experimental values and Yates correlation may be imputable to the absence of influence by particle size and density in Yates correlation. 


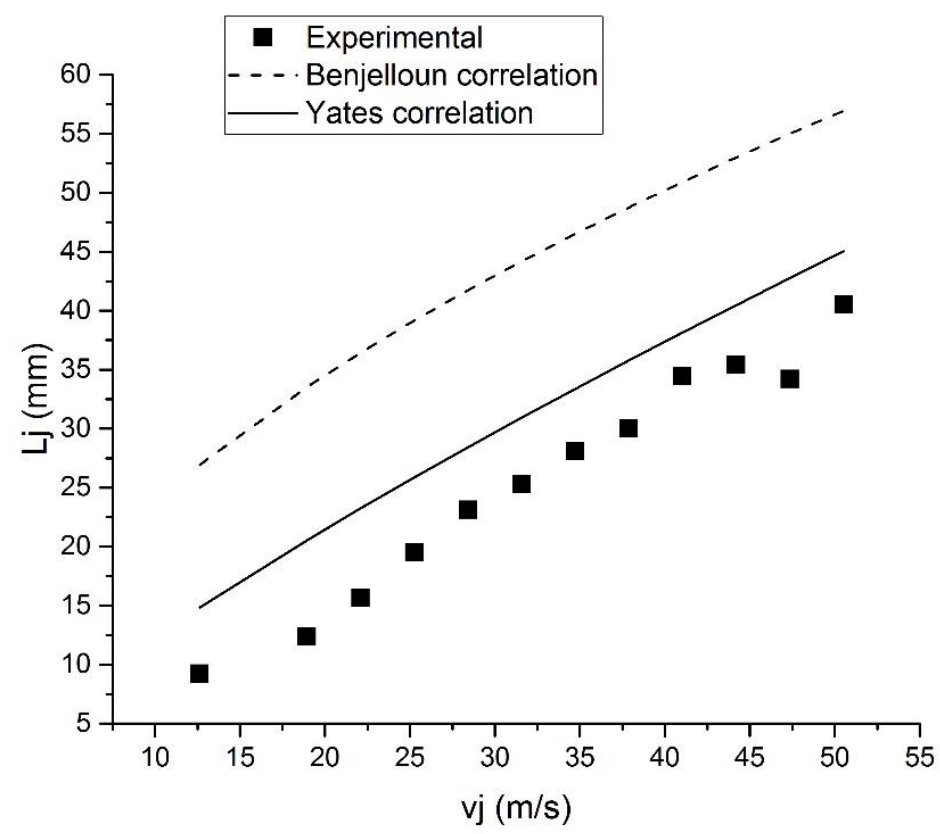

Figure 13 - Comparison between prediction from the Benjelloun correlation and experimental results (Material A, double jet configuration)

In this study, jet penetration was measured at different jet velocities for the different materials and the different particle size described in section 2.2. The results are represented in Figure 14.

By introducing the dimensionless particle size $d_{p} / d_{o}$, where $d_{p}$ is the particle size and $d_{o}$ is the orifice diameter, it was possible to quantify the effect of the particle size on the jet penetration. At a given $\mathrm{Fr}$, increasing the particle size causes the decreasing of the jet penetration (Figure 15), as also confirmed in literature $[8,9,25]$. Furthermore, the experiments showed a plateau value at $d_{p} / d_{o} \rightarrow 0$, which was not observed before due to the different conditions investigated (i.e. large particles do not show the plateau behaviour) [7]. 

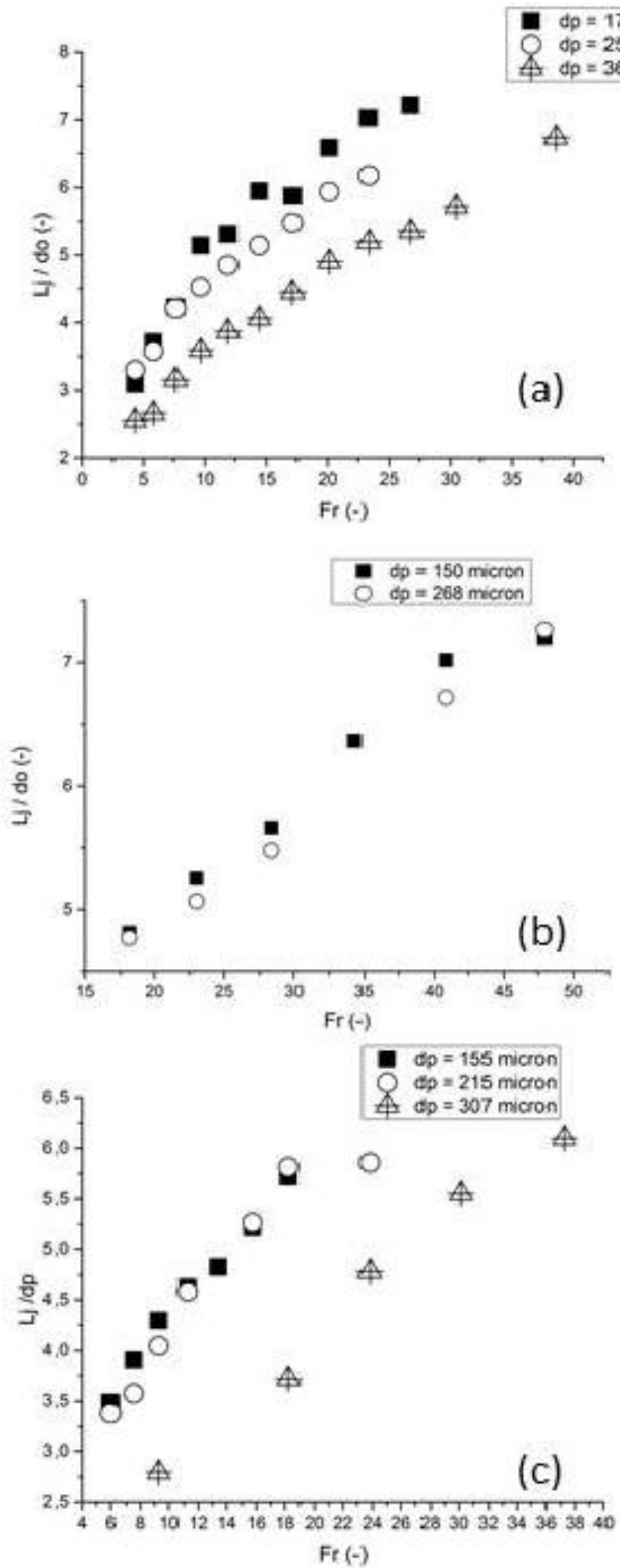

Figure 14 - Dimensionless jet penetration vs. Froude number (a) Material A, (b) Material B, (c) Material C 


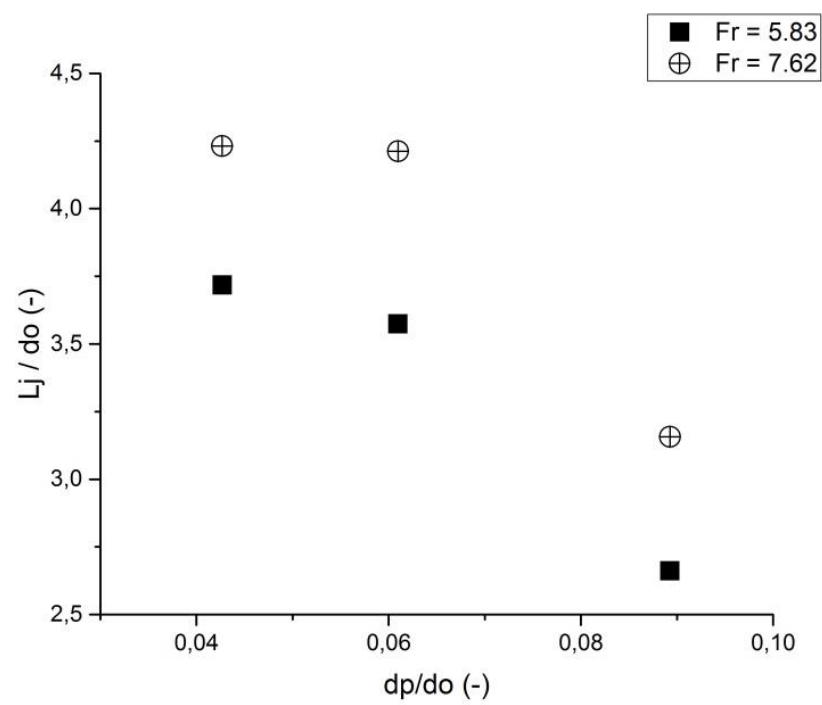

Figure 15 - Dimensionless jet penetration vs. dimensionless particle size at given Fr, Material A

Equation (2) has been applied to model the data gathered, giving different values of the parameters $\alpha$ and $\beta$ (Table 2).

\begin{tabular}{|c|c|c|c|}
\hline \multicolumn{4}{|c|}{ Material A } \\
\hline$\alpha$ & 1.79 & 1.71 & 1.29 \\
\hline$\beta$ & 0.43 & 0.43 & 0.44 \\
\hline \multicolumn{4}{|c|}{ Material B } \\
\hline \multicolumn{2}{|r|}{$d_{p}=150 \mu \mathrm{m}$} & \multicolumn{2}{|r|}{$d_{p}=268 \mu \mathrm{m}$} \\
\hline$\alpha$ & 1.32 & \multicolumn{2}{|r|}{1.23} \\
\hline$\beta$ & 0.44 & \multicolumn{2}{|r|}{0.46} \\
\hline \multirow{2}{*}{\multicolumn{4}{|c|}{$\begin{array}{l}\text { Material C } \\
\qquad d_{p}=215 \mu \mathrm{m}\end{array}$}} \\
\hline & & & \\
\hline$\alpha$ & 1.66 & 1.51 & 0.93 \\
\hline$\beta$ & 0.42 & 0.44 & 0.5 \\
\hline
\end{tabular}

Table 3 - Model parameter

A sensitivity analysis was then carried out on these parameters, with the results presented in Figure 16.

The parameter $\beta$ does not show any particular trend when varying material and particle size (Figure $16(b)$ ), with a standard deviation from the mean value equal to $6 \%$. 
On the other hand, the parameter $\alpha$ shows a clear trend when varying both the particle size and density (Figure $16(a)$ ). The effect of the particle size is that previously explained: when the particle size increases, $\alpha$ decreases, and when the particle size approaches 0 a plateau in $\alpha$ is observed. Furthermore, when increasing the particle density at a given particle size, the value of $\alpha$ decreases.

Taking into account these trends, the following corrected formula is proposed

$$
\frac{L_{j}}{d_{o}}=\alpha \operatorname{Fr}^{\beta} \frac{1}{\left(1+d_{p} / d_{o}\right)^{\gamma}}\left(\frac{\rho_{o}}{\rho_{p}}\right)^{\delta}
$$

Equation (3) satisfies the dependencies on Fr, particle size and particle density: given the material (that is particle size and density), the jet penetration increases with Fr; given $\mathrm{Fr}$ and $\frac{\rho_{o}}{\rho_{p}}$, when decreasing the particle size the jet penetration increases, leading to a plateau when $d_{p}$ approaches zero; furthermore, given $\mathrm{Fr}$ and $d_{p}$, an increase in the particle density corresponds to a decrease in the jet penetration.

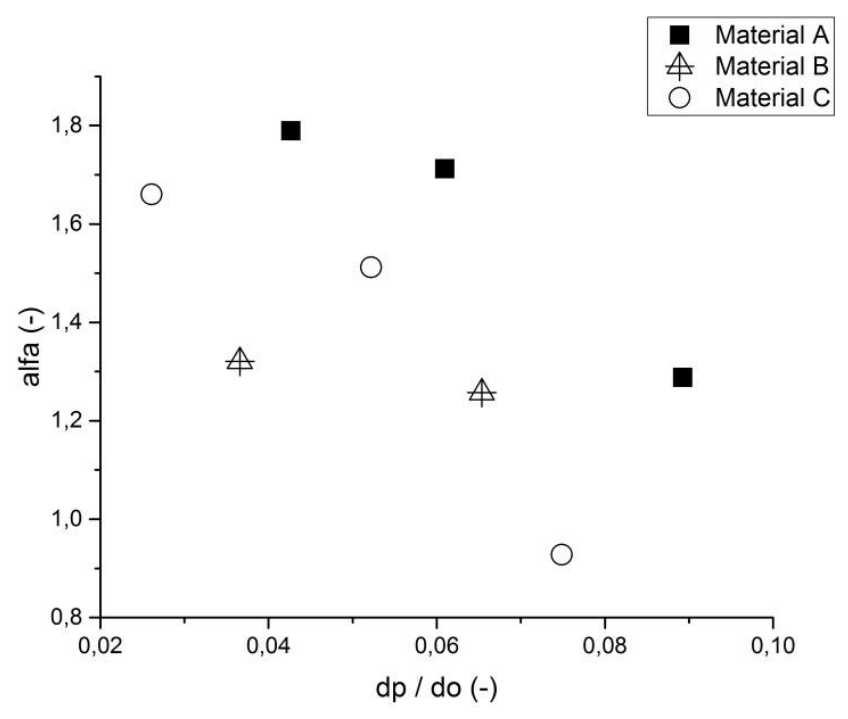

(a) 


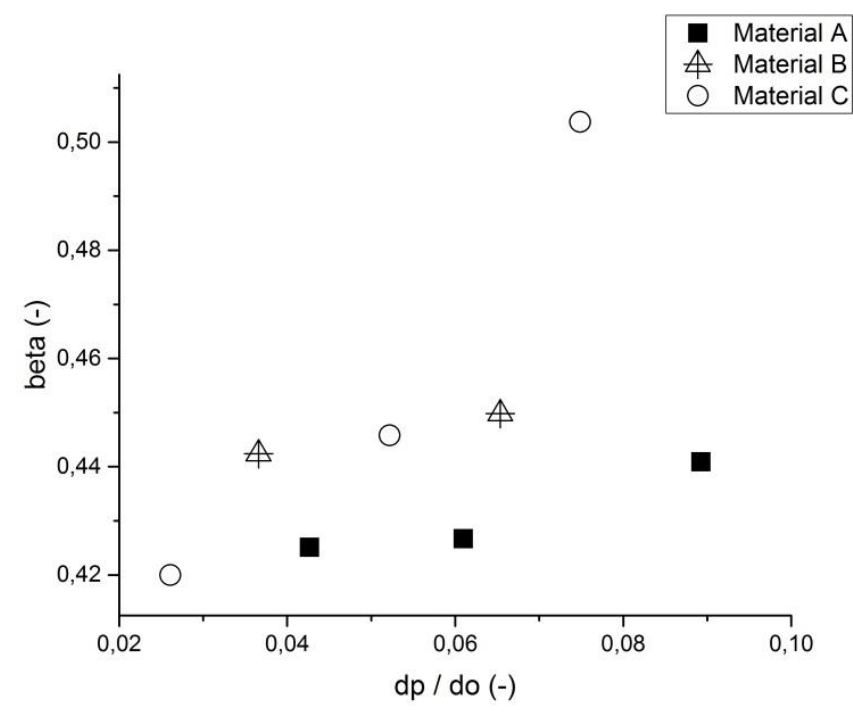

(b)

Figure $16-\alpha(\mathrm{a})$ and $\beta(\mathrm{b})$ sensitivity analysis

The regression of the experimental data gathered in this work allowed the parameters in formula 3 to be estimated, as shown in Table 3.

\begin{tabular}{cccc}
\hline$\alpha$ & $\beta$ & $\gamma$ & $\delta$ \\
\hline 61.2 & 0.4 & 5.6 & 0.4
\end{tabular}

Table 3 - Correlation parameters

To judge the quality of the results obtained, a statistical study was carried out by analysing the residuals and evaluating both the variance of the error term $M S E=0.09$ and the adjusted coefficient of determination $R_{c}^{2}=0.934$. The residuals appeared as scattered, with no particular trend or structure recognizable, giving a positive feedback on the quality of the regression. A one sample t-test has also been carried out on the resiudals, confirming that the mean of the residual approximates 0 . Furthermore the computed value of $R_{c}^{2}$ was close to 1.

As shown in Figure 17 to 19, the data are well fitted from the regression, with a maximum discrepancy of $10 \%$ in the case of material B with a particle size of $d_{p}=268 \mu \mathrm{m}$ (Figure 18 (b)).

A definitive mechanistic explanation for the inadequacy of a purely hydrodynamic scaling (based on the use of Fr alone) to correlate the experimental data cannot be offered at the moment. But at least two arguments may be inferred from the reported data. On one hand, purely hydrodynamic scaling has already proven to fall short in predicting fundamental properties of dense gas fluidized beds, like the onset of bubbling, in beds of small and/or light particles as interparticle forces (of frictional and/or cohesive nature) come into play 
[33]. On the other hand, the strong dependence on $d_{p} / d_{o}$ expressed by the fairly large value of $\gamma$ may indicate that the emulsion phase of the bed departs from behaving like a "continuum" and displays its inherently discrete nature as the ratio $d_{p} / d_{o}$ increases. Accordingly, it may be speculated that increasing $d_{p} / d_{o}$ promotes gas "leakage" across the jet boundaries into the emulsion phase, hence a reduction of the extension of the visible jetting region $[34,35]$. Further investigation is required to better characterize the role of these factors, and the likely interaction between them.

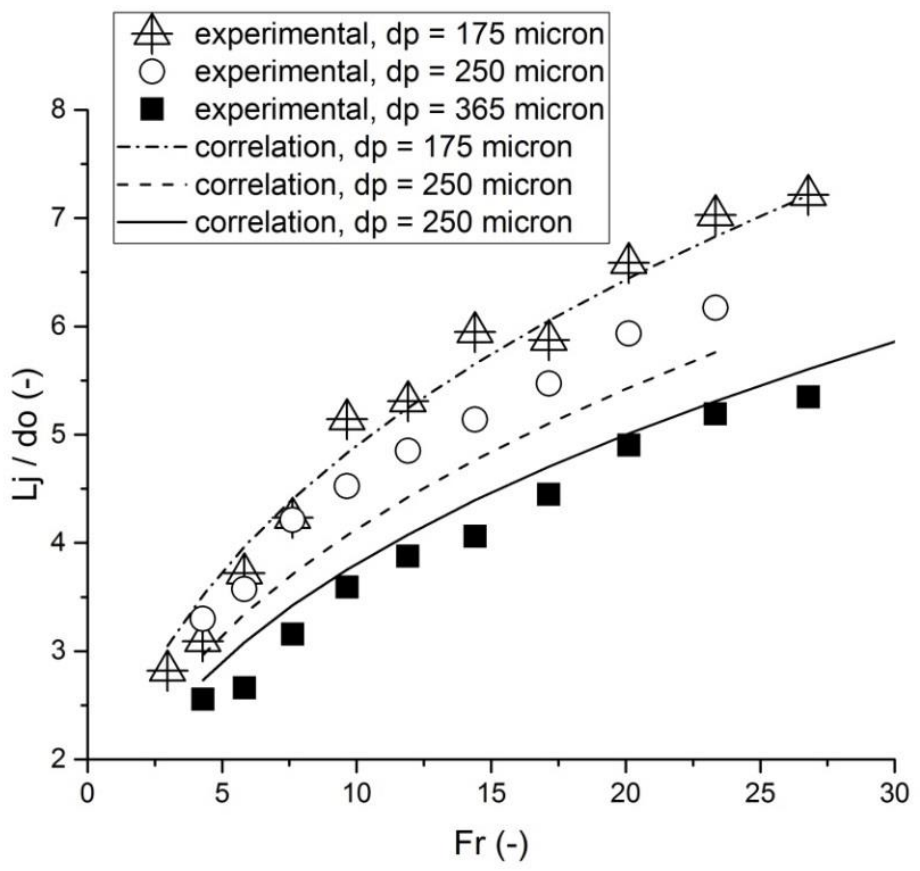

Figure 17 - Material A data fitted 

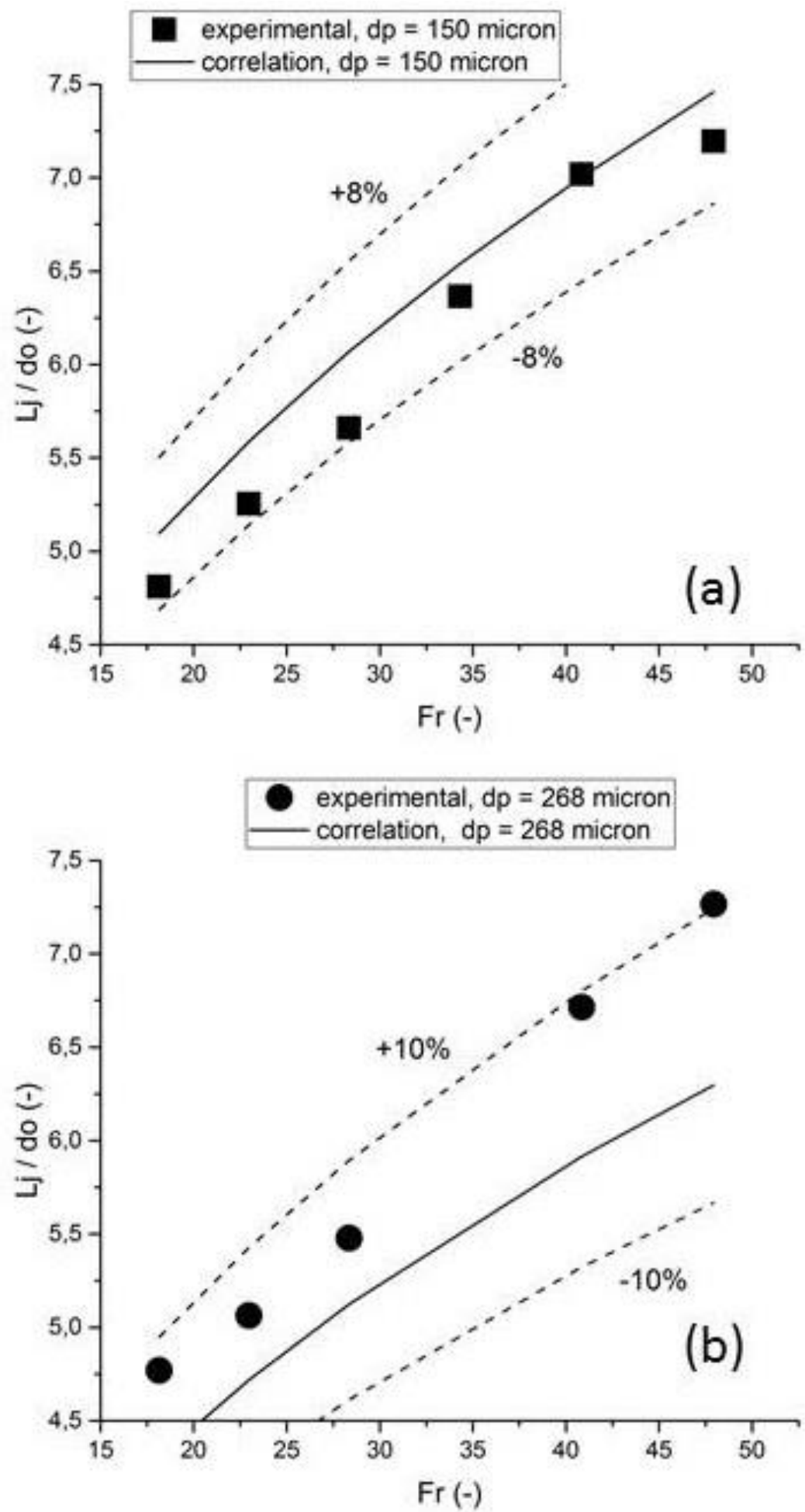

Figure 18 - Material B data fitted, (a) $d_{p}=150 \mu \mathrm{m}$, (b) $d_{p}<268 \mu \mathrm{m}$ 

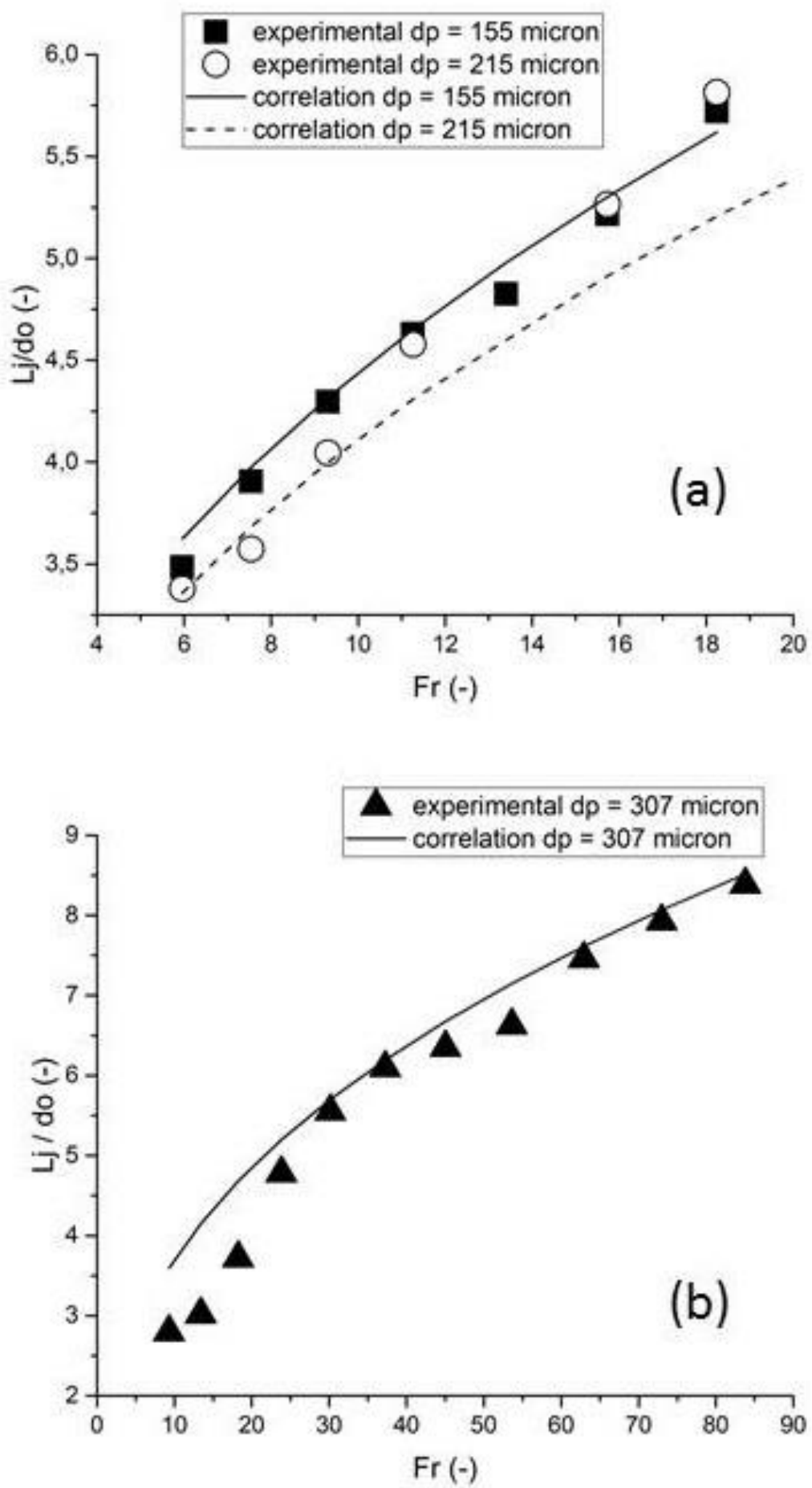

Figure 19 - Material C data fitted, (a) $d_{p}=155 \mu \mathrm{m}$ and $d_{p}=215 \mu \mathrm{m}$, (b) $d_{p}=307 \mu \mathrm{m}$ 


\section{Conclusions}

The innovative X-ray imaging technique has been employed to investigate the features of a nozzle-type gas distributor, with a specific focus on jet-emulsion phase interaction patterns and jet penetration.

Comparing the observed jet penetration with predictions from previous correlations, these are shown to overestimate the jet penetration, due to a stabilizing effect exerted by the walls on the jet in 2-D reactors.

Based on the experimental data obtained, a new and improved empirical correlation to predict the jet penetration has been proposed, whose validity has been checked with a variety of gas velocities, particle densities and sizes. . Departure from a purely hydrodynamic scaling are speculatively explained in terms of gas leakage across the jet boundaries and interparticle forces.

Further study is intended to address different operative conditions (e.g. pressure and temperature) and to compare primary and secondary injections jet penetration by employing the same experimental technique.

\section{References}

[1] W.-C. Yang, Handbook of fluidization and fluid-particle systems, 2003.

[2] D. Kunii, O. Levenspiel, Butterworth-Heinemann Series in Chemical Engineering, 1991.

[3] C. Briens, F. Berruti, L. Feng, J. McMillan, The 13th International Conference on Fluidization - New Paradigm in Fluidization Engineering, Fluid. Nanopowders Exp. Model. Appl. (2010).

[4] Q. Zhang, T.J. Jamaleddine, C. Briens, F. Berruti, J. McMillan, Jet attrition in a fluidized bed. Part I: Effect of nozzle operating conditions, Powder Technol. 229 (2012) 162169. doi:10.1016/j.powtec.2012.06.025.

[5] Q. Zhang, T.J. Jamaleddine, C. Briens, F. Berruti, J. McMillan, Jet attrition in a fluidized bed. Part II: Effect of fluidized bed hydrodynamics, Powder Technol. 229 (2012) 170177. doi:10.1016/j.powtec.2012.06.026.

[6] D. Musmarra, Influence of Particle Size and Density on the Jet Penetration Length in Gas Fluidized Beds, Ind. Eng. Chem. Res. 39 (2000) 2612-2617. doi:10.1021/ie9907831.

[7] M.D. Merry, Penetration of Vertical Jets into Fluidized Beds, AIChE J. 21 (1975) 507510. doi:10.1002/aic.690210312.

[8] M.D. Merry, Penetration of a Horizontal Gas Jet Into a Fluidized Bed, AIChE J. 49 (1971) 189. 
[9] N.A. Shakova, Discharge of turbulent jets into a fluidized bed, J. Eng. Physiscs. 14 (1968) 32-36.

[10] D. Newton, Revealing the secrets of fluidised beds Exploiting links between academia and industry, Ingenia. (2004) 47-52.

[11] J.G. Yates, S.S. Cobbinah, D.J. Cheesman, S.P. Jordan, Particle attrition in fluidized beds containing opposing jets, AIChE J. Symp. Ser. 87 (1991) 13-19.

[12] M. Pore, G.H. Ong, C.M. Boyce, M. Materazzi, J. Gargiuli, T. Leadbeater, A.J. Sederman, J.S. Dennis, D.J. Holland, A. Ingram, P. Lettieri, D.J. Parker, A comparison of magnetic resonance, $\mathrm{X}$-ray and positron emission particle tracking measurements of a single jet of gas entering a bed of particles, Chem. Eng. Sci. 122 (2015) 210-218. doi:10.1016/j.ces.2014.09.029.

[13] P. Lettieri, J.G. Yates, New Generation X-ray Imaging for multiphase systems, in: Fluid. XIV, Leeuwenhorst Noordwijkerhout, The Netherlands, 2013: pp. 641-648.

[14] C.Y. Wen, Y.H. Yu, A generalized method for predicting the minimum fluidization velocity, AIChE J. 12 (1966) 610-612.

[15] D. Geldart, Types of gas fluidization, Powder Technol. 7 (1973) 285-292. doi:10.1016/0032-5910(73)80037-3.

[16] S. Tebianian, N. Ellis, P. Lettieri, J.R. Grace, X-ray imaging for flow characterization and investigation of invasive probe interference in travelling fluidized bed, Chem. Eng. Res. Des. 104 (2015) 191-202. doi:10.1016/j.cherd.2015.08.006.

[17] D. Newton, C. Grant, B. Gamblin, X-ray imaging to reveal FCC catalyst and gas interactions, HTI Q. (1994) 41-45.

[18] K.-T. Wu, Bubble coalescence from multiple entry nozzles in fluidized beds, University College London, 1997.

[19] J.G. Yates, V. Bejcek, D.J. Cheesman, Jet penetration into fluidized bed at elevated pressure, Fluid. 5. (1986) 79-86.

[20] M. Filla, L. Massimilla, D. Musmarra, S. Vaccaro, Pressure fluctuations associated with gas injection in fluidized beds, in: Fluid. 5, 1986: pp. 71-78.

[21] V.A. Basov, V.I. Markhevka, T.K.. Melik-Akhnazanov, D.I. Orochke, Investigation of the structure of a nonuniform fluidized bed, Intern. Chem. Eng. 9 (1969) 263-266.

[22] P. Liseth, Mixing of merging bouyant jets in stagnant recieving water of uniform density, University of California, Berkeley, 1970.

[23] P. Liseth, Wastewater disposal by submerged manifolds, J. Hydraul. Eng. 102 (1976) $1-14$.

[24] W.-C. Yang, D.L. Keairns, Design and Operating parameters for a fluidized bed agglomerating combustor/gassifiers, Cambridge Univ. Press. (1978) 208-214. 
[25] R. Hong, H. Li, H. Li, Y. Wang, Studies on the inclined jet penetration length in a gassolid fluidized bed, Powder Technol. 92 (1997) 205-212. doi:10.1016/S00325910(97)03238-5.

[26] F.V. Benjelloun, Determination des longueurs de jets de gaz horizontaux dans lits fluidises, La Fluid. 5 (1991) 108-115.

[27] F.A. Zenz, Bubble formation and grid design, IChemE Symp. Ser. 30 (1968) 136-139.

[28] T.R. Blake, C.Y. Wen, C.A. Ku, The correlation of jet penetration measurements in fluidized beds using nondimensional hydrodynamic parameters, AIChE Symp. Ser. 80 (1984) 42-51.

[29] L. Massimilla, Gas jets in fluidized beds, Fluidization. (1985).

[30] T. Kimura, K. Horiuchi, T. Watanabe, M. Matsukata, T. Kojima, Experimental study of gas and particle behavior in the grid zone of a jetting fluidized bed cold model, Powder Technol. 82 (1995) 135-143. doi:10.1016/0032-5910(94)02913-9.

[31] C.R. Müller, D.J. Holland, J.F. Davidson, J.S. Dennis, L.F. Gladden, A.N. Hayhurst, M.D. Mantle, A.J. Sederman, Geometrical and hydrodynamical study of gas jets in packed and fluidized beds using magnetic resonance, Can. J. Chem. Eng. 87 (2009) 517-525. doi:10.1002/cjce.20191.

[32] C.Y. Wen, N.R. Deole, L.H. Chen, A study of jets in a 3-dimensional gas fluidized bed, Powder Technol. 31 (1981) 175-184.

[33] M. Poletto, P. Salatino, L. Massimilla, Fluidization of solids with $\mathrm{CO} 2$ at pressures and temperatures ranging from ambient to nearly critical conditions, Chem. Eng. Sci. 48 (1993) 617-621.

[34] H.S. Caram, K.-K. Hsu, Bubble formation and gas leakage in fluidized beds, Chem. Eng. Sci. 41 (1986) 1445-1453.

[35] M. Fiorentino, A. Marzocchella, P. Salatino, Segregation of fuel particles and volatile matter during devolatilization in a fluidized bed reactor - I. Model development, Chem. Eng. Sci. 52 (1997) 1893-1908. doi:10.1016/S0009-2509(97)00018-3. 